\title{
BMJ Open Women's satisfaction with midwife-led continuity of care: an observational study in Palestine
}

\author{
Berit Mortensen (D) , ${ }^{1,2}$ Lien M Diep, ${ }^{3}$ Mirjam Lukasse, ${ }^{4,5}$ Marit Lieng, ${ }^{2,6}$ \\ Ibtesam Dwekat, ${ }^{7}$ Dalia Elias, ${ }^{8}$ Erik Fosse ${ }^{1,2}$
}

To cite: Mortensen B, Diep LM, Lukasse M, et al. Women's satisfaction with midwife-led continuity of care: an observational study in Palestine. BMJ Open 2019;9:e030324. doi:10.1136/ bmjopen-2019-030324

- Prepublication history and additional material for this paper are available online. To view these files, please visit the journal online (http://dx.doi. org/10.1136/bmjopen-2019030324).

Received 08 March 2019 Revised 08 July 2019

Accepted 09 0ctober 2019

Check for updates

(c) Author(s) (or their employer(s)) 2019. Re-use permitted under CC BY-NC. No commercial re-use. See rights and permissions. Published by BMJ.

For numbered affiliations see end of article.

Correspondence to Berit Mortensen; beritmor@me.com

\section{ABSTRACT}

Objectives A midwife-led continuity model of care had been implemented in the Palestinian governmental health system to improve maternal services in several rural areas. This study investigated if the model influenced women's satisfaction with care, during antenatal, intrapartum and postnatal period.

Design An observational case-control design was used to compare the midwife-led continuity model of care with regular maternity care.

Participants and setting Women with singleton pregnancies, who had registered for antenatal care at a rural governmental clinic in the West Bank, were between 1 to 6 months after birth invited to answer a questionnaire rating satisfaction with care in 7-point Likert scales.

Primary outcome The mean sum-score of satisfaction with care through the continuum of antenatal, intrapartum and postnatal period, where mean sum-scores range from 1 (lowest) to 7 (highest).

Secondary outcome Exclusive breastfeeding.

Results Two hundred women answered the questionnaire, 100 who received the midwife-led model and 100 who received regular care. The median time point of interview were 16 weeks postpartum in both groups. The midwifeled model was associated with a statistically significant higher satisfaction with care during antenatal, intrapartum and postnatal period, with a mean sum-score of 5.2 versus 4.8 in the group receiving regular care. The adjusted mean difference between the groups' sum-score of satisfaction with care was $0.6(95 \% \mathrm{Cl} 0.35$ to 0.85$), \mathrm{p}<0.0001$. A statistically significant higher proportion of women who received the midwife-led continuity model of care were still exclusively breastfeeding at the time point of interview, $67 \%$ versus $46 \%$ in the group receiving regular care, an adjusted $O R$ of 2.56 (1.35 to 4.88 ) $p=0.004$.

Conclusions There is an association between receiving midwife-led continuity of care and increased satisfaction with care through the continuum of pregnancy, intrapartum and postpartum period, and an increased duration of exclusive breastfeeding.

Trial registration number NCT03863600

\section{BACKGROUND}

Yearly, more than 300000 women die from preventable causes related to pregnancy and childbirth, and $99 \%$ of them are from lowand middle-income countries. ${ }^{1}$ It is estimated

\section{Strengths and limitations of this study}

- The study adds new information from a low-middle income country to existing evidence on midwife-led continuity of care.

- The study's complete data obtained from face-toface interviews brings information on satisfaction with care from a marginalised group of women.

- The study investigated to what extent a pragmatic implementation could improve continuity with care in a low resource setting.

- The main limitation of this study is the observational, retrospective design comparing groups with potential unmeasured confounders.

- Not knowing the woman's village of origin and in which governmental hospital the women gave birth, could represent potential bias. However, the women in both groups represented a quite similar rural population from villages in different regions in the West Bank.

that in the shadow of each maternal death, between 50 and 100 women suffer severe maternal morbidity. ${ }^{12}$ A new-born child's prospects of survival, good health and well-being is closely linked to their mother's survival, health and well-being. ${ }^{2}$ Several studies investigating disrespectful and abusive treatment of women in maternity care, suggest this may explain why many women choose not to use available services. ${ }^{3} 4$ In a literature review from developing countries in 2015, Srivastava et al investigated what determines women's satisfaction with maternal healthcare. ${ }^{5}$ They found that being treated respectfully, in terms of courtesy and non-abuse, irrespective of socio-cultural or economic context, is especially important to women. ${ }^{5}$ Interpersonal behaviour was the most prominent reported determinant of maternal satisfaction, more than structural factors as cleanliness and physical environment. ${ }^{5}$ Around the world women seek dignity, empathy and respect while obtaining maternal care and women's experience with disrespectful care and abuse 
in healthcare has been investigated in both low- and highincome settings. ${ }^{46}$ Based on the research evidence, the WHO has recommended interventions that scales up midwifery and facilitate continuity with care to enhance respectful relations in maternal care. ${ }^{1-11}$

Midwife-led continuity of care described in the literature, can be organised as case-load or team-midwifery models. ${ }^{12}$ In the case-load model one designated midwife cares for a group of up to 45 women, while in teammidwifery four to six midwives share the care of a group of up to 360 women. In both models, women are followed up through the continuum of pregnancy, intrapartum and postnatal period. The case-load model facilitates an individual relationship between the woman and her midwife. Ideally, in both models, women will be cared for during labour by a midwife they know from antenatal care. ${ }^{72} \mathrm{~A}$ Cochrane review on continuity of midwifery care models, conducted by Sandall et al in 2016, reported improved health outcomes for women and babies. Several studies in the review also confirm satisfaction with midwife-led continuity models of care, but the studies lacked consistency in how satisfaction with continuity of care was measured. ${ }^{8}$ Perriman and Davis identified in a systematic integrative review from 2015, four suitable instruments to measure satisfaction with continuity of care through the continuum of pregnancy, birth and the early postpartum period. ${ }^{13}$

\section{Palestinian context}

According to Ministry of Health's 2016 report there were 208 midwives employed at the West Bank's governmental hospitals covering 36050 births and care in postnatal wards. Palestinian midwives worked in an overcrowded, understaffed and fragmented governmental maternity care system. ${ }^{14} 15$ Midwives scope of practice within the governmental system was limited to labour and postnatal care in hospitals. If midwives provided antenatal care, they were in an assisting role. ${ }^{15}$ In such environment it was challenging to establish good relations and to meet each woman's individual needs. In a study from 2006, Giacaman et al identified that Palestinian women were not satisfied with the place they gave birth, and that their choice were constrained by availability, affordability and limited access due to Israeli military closures and sieges. ${ }^{16}$ To address the challenge faced by Palestinian women living under Israeli occupation in rural areas in the West Bank, the Palestinian Ministry of Health implemented a modified midwife-led case-load model of care, in cooperation with a Norwegian humanitarian organisation, Norwegian Aid Committee. The model was implemented between 2013 to 2016 in six governmental hospitals from where midwives provided outreaching antenatal and postnatal care in 37 rural villages. The implementation was associated with increased number of antenatal visits, number of detected pregnancy complications referred to higher level of care and number of postnatal home visits. ${ }^{17}$ It was further associated with reduced unplanned caesarean sections and induced labour, and improved important maternal and neonatal outcomes. ${ }^{18}$ When the midwife-led model was tested in the region of Ramallah between 2007 and 2011, the midwives described in a qualitative study, how the model enabled them to provide personalised care related to the individual woman's needs and how the broad scope of practice gave them new and important experience and knowledge. ${ }^{19}$

The aim of this study was to investigate if and how a modified case-load midwife-led continuity model of care, in the governmental system in Palestine, influenced rural women's satisfaction with care, through the continuum of antenatal, intrapartum and postnatal period. A secondary aim was to explore the association between the model and duration of exclusive breastfeeding.

\section{METHODS \\ Study design}

An observational case-control design was used to compare satisfaction with care. The cases were women who had received the midwife-led continuity model and controls were women who had received regular maternity care, through the continuum of antenatal, intrapartum and postnatal period. Common inclusion criteria for cases and controls were having a singleton pregnancy, having registered for antenatal care at a rural governmental clinic in the West Bank in the regions where the midwife-led model of care had been implemented and having given birth between the last 1 to 6 months.

\section{Power and sample size}

The power calculations were based on the results from a recent study in Australia, as we found no available studies on satisfaction with midwife-led continuity models of care in low-middle income countries. ${ }^{20}$ A sample of 164 to 186 (82 to 93 in each group) was required to detect a difference of $20 \%$ between the control and intervention group's proportions of satisfaction, given a significance level of $0.05 \%$ and $80 \%$ power. Considering the novel context, we decided to collect answers from 200 women, 100 in each group, to assure enough power.

\section{Models of care}

The midwife-led continuity of care model, modified to the Palestinian setting, implies that midwives who work in governmental hospitals was assigned to weekly visits to rural areas. Midwives drove from their base at their governmental hospitals in designated marked cars, to provide antenatal care in rural clinics and postnatal home visits. Each midwife visited the same area and clinic each week, thereby following up the same case-load of between 30 to 100 women to enhance relational continuity. The midwife from the regional hospital had an autonomous role and relieved the regular nurses and doctors at the rural governmental clinics from antenatal care. She involved physicians when needed and referred to higher level of care when complications occurred. The obligation to work full-time and the heavy workload at the hospital 
prevented the midwives from being on call to attend labour and birth, as such the women were not assured having a known midwife during labour. A more detailed framework of the model is described elsewhere. ${ }^{1718}$

Regular maternal care for women living in rural villages was offered from the governmental clinics and/or private medical doctors. Around $70 \%$ of the rural women registered for antenatal care in governmental clinics, where regular care providers were nurses or midwives and medical doctors. ${ }^{17}$ Besides maternal care, governmental providers in regular care were also responsible for general patient treatment, vaccinations and minor emergency cases. The nurse or midwife in regular care would assist the physician by doing necessary tests, before the pregnant woman consulted the physician. Physicians alternated between clinics, while nurses were mainly permanent staff. Healthcare providers in community clinics offering regular care had no working relation to the hospitals. Women receiving private antenatal care could potentially meet their doctor if they gave birth at a private hospital.

\section{Participants and data collection}

Women were asked to participate when they came with their child for vaccination at the same governmental clinic where they received antenatal care. Two midwives, who were not working with governmental primary healthcare, nor in the midwife-led continuity model, were trained in data collection. The research midwives travelled to rural villages scattered in different regions of the West Bank, that either offered the midwife-led continuity model or regular care. They invited eligible women to participate after providing them an information and consent form in Arabic, explaining the study. Women were assured anonymity if they participated, and that they would not be affected negatively if they did not accept to participate. To assure anonymity, the women were informed that neither their identity, village, clinic nor birth facility could be traced. Their consent was given orally by accepting to answer the questionnaire by an interview. The research midwives collected the data in the women's homes or in a private place in the clinic. Each woman was given an Arabic version of the questionnaire. The research midwife then filled the questionnaire forms while interviewing the women to assure they understood the questions. The research midwives tested how long time the interviews took and how to approach the women, by conducting five test-interviews each before starting the data collection. These interviews did not result in adjustments of the questionnaires and were not included in the study. The interview was estimated to take $30 \mathrm{~min}$. The research midwives transferred the women's responses to the University of Oslo via the web form, 'nettskjema.no'.

\section{The questionnaire}

The questionnaire (online supplementary file 1) was based on previous studies measuring satisfaction with midwife-led continuity and evaluated as suitable for this purpose. ${ }^{132021}$ The questionnaire included 62 questions measuring women's satisfaction with antenatal, intrapartum and postpartum care using a 7-point Likert scale, where usually 1 signified 'disagree strongly' and 7 signified 'agree strongly'. Women were further asked to what extent they received care during intrapartum and postpartum period from the provider they knew from antenatal care, and they were asked about their breastfeeding practice. The participants were invited to add recommendations to improve governmental services, in an open text section in the questionnaire. The content of the final questionnaire was tested for contextual and cultural sensitivity with a group of five Palestinian midwives. After minor adjustments the questionnaire was translated to Arabic by a professional translator, retested and adjusted for accuracy.

\section{Outcomes}

Primary outcome was the mean sum-score of satisfaction with care through the continuum of antenatal, intrapartum and postpartum period. Secondary outcomes were satisfaction with care related to the different episodes of care, and proportion of women that still practiced exclusive breastfeeding at time point of interview. Grade of continuity was measured by number of women who received care from their antenatal midwife during labour, at postnatal hospital ward and/or at home visits.

\section{Statistical analysis}

Difference in characteristics between the intervention and control groups were analysed by two independent samples t-tests, Mann-Whitney U tests, $\mathrm{X}^{2}$ or Fisher's exact tests, as appropriate.

The Likert scale ordinal variables were highly skewed and first analysed by conducting ordinal regression because this method had been used in previous studies using similar Likert scales. ${ }^{19}$ After fitting the ordinal regression, the proportional odds assumption was inspected by a Brant test, using brant command in Stata/ SE, V.14. Results from the test showed that proportional odds assumption was violated for several ordinal outcomes.

Therefore, we summarised the answers, and the groups' mean sum-scores of satisfaction were compared by bootstrapping linear regression. The primary outcome, mean sum-score of satisfaction through the continuum of antenatal, intrapartum and postnatal care, included 53 different questions of satisfaction. Negative questions, such as: I felt that nobody really cared for me during labour and birth, were turned positive so that satisfaction could be interpreted equally in all questions and the mean sum-scores thereby read as 1 (lowest) and 7 (highest). One question from the antenatal period was not included, as it investigated if occupation soldiers or settlers limited women's access to the clinic and not satisfaction with care. Neither were eight questions involving satisfaction with care during home visits, as it only applied to 
the group receiving the midwife-led model. The questions of satisfaction included in the mean sum-score variables were assessed for internal consistency and Cronbach's Alpha was between 0.90 and 0.95 . Factors which could influence the difference between groups were included for adjusting. Adjusted bias-corrected and accelerated bootstrap estimates with $95 \%$ CIs were given for non-normally distributed ordinal outcomes and based on 10000 bootstraps. For breastfeeding practice as binary outcome, multiple logistic regression analyses were used to test the difference between the groups and adjusting for possible confounding variables.

Significance level was set at 0.05 . The analyses were performed with IBM SPSS 25.

\section{Patient and public involvement}

Participants were not directly involved in the planning of the study, but in testing the feasibility of the questionnaire. The results will be disseminated in scientific publications, in public media and in local and international conferences.

\section{Ethical considerations}

The Palestinian Ministry of Health approved the study and the research assistants' access to the health facilities, allowing them to contact women who had registered at the governmental clinic to ask them for consent to participate in the study. There was no research ethic committee established in the West Bank that could grant local ethical approval.

\section{RESULTS}

\section{Participants characteristics}

Between 1 May, 2017, to 31 May, 2018, 200 women from 20 villages answered the questionnaire, 100 who received the midwife-led continuity model and 100 who received regular care. There were 26 women who abstained from participating, of them 22 received regular care and four received midwife-led care. Groups characteristics, presented in table 1 , were mainly homogenous. The time point of interview was median 16 weeks postpartum in both groups, with no statistically significant differences related to age, education, employment or parity. Less

\begin{tabular}{|c|c|c|c|}
\hline Characteristics & Midwife-led care $(n=100)$ & Regular care $(n=100)$ & P value* \\
\hline Time point of interview/weeks since birth $\dagger$ & $16.0(11.0-18.8)$ & $16.0(8.0-22.8)$ & 0.499 \\
\hline Age $\ddagger$ & $26.6(5.8)$ & $26.3(5.6)$ & 0.688 \\
\hline Age at marriage $\dagger$ & $20.3(18.0-22.0)$ & $20.7(18.0-22.8)$ & 0.812 \\
\hline Age at first birth $\dagger$ & $21.5(19.0-23.0)$ & $21.8(19.3-23.0)$ & 0.997 \\
\hline Nulliparous§ & 32 & 38 & 0.459 \\
\hline Multiparous§ & 68 & 62 & 0.459 \\
\hline Number of previous pregnancies $†$ & $2.0(1.0-3.0)$ & $2.0(1.0-3.0)$ & 0.125 \\
\hline Number of live born children† & $2.0(1.0-3.0)$ & $2.0(1.0-3.0)$ & 0.104 \\
\hline \multicolumn{4}{|l|}{ Education level§ } \\
\hline Up to master's degree after high school & 46 & 37 & 0.251 \\
\hline High school & 54 & 63 & 0.251 \\
\hline \multicolumn{4}{|l|}{ Employment§ } \\
\hline $\begin{array}{l}\text { Woman has employment (full-time or part- } \\
\text { time) }\end{array}$ & 15 & 10 & 0.393 \\
\hline Woman not employed & 85 & 90 & 0.393 \\
\hline Husband has regular employment & 64 & 49 & 0.020 \\
\hline Husband employed now and then & 32 & 50 & 0.014 \\
\hline Husband not employed & 4 & 1 & 0.369 \\
\hline \multicolumn{4}{|l|}{ Social§ } \\
\hline Husband must live outside home to work & 9 & 15 & 0.119 \\
\hline Women's parents live in same village & 34 & 63 & 0.0001 \\
\hline Not smoking§ & 94 & 86 & 0.097 \\
\hline
\end{tabular}

*Mann-Whitney $\mathrm{U}$ tests, independent samples t-test or $\mathrm{X}^{2}$ tests.

†Median (IQR).

‡Mean (SD).

$\S \%$. 
Table 2 Characteristics of obtained care

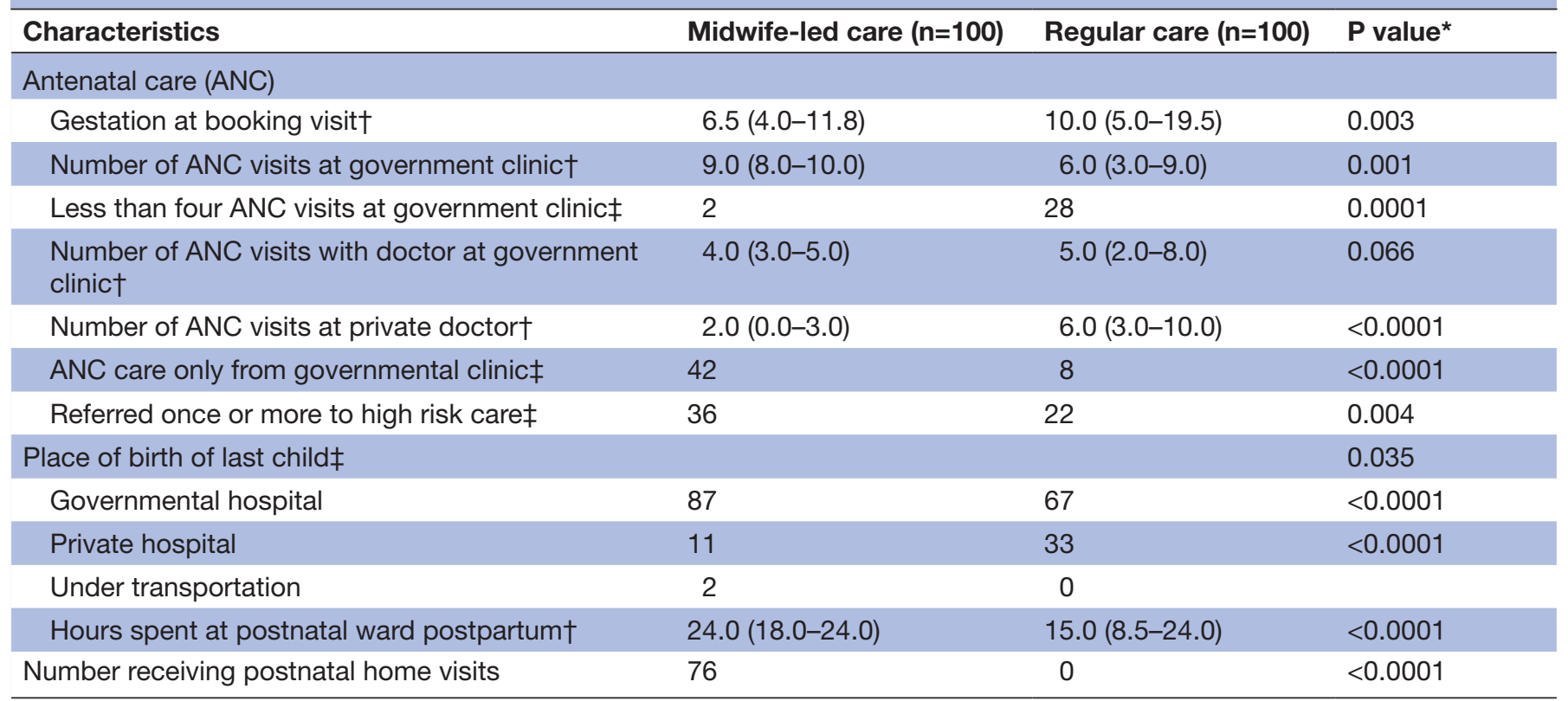

${ }^{*}$ Mann-Whitney $\mathrm{U}$ or $\mathrm{X}^{2}$ tests.

†Median (IQR).

$\ddagger \%$

women who received the midwife-led model of care had parents living in the same village as themselves.

\section{Characteristics of obtained care}

Women who received the midwife-led continuity model of care booked significantly earlier for antenatal care at the governmental clinic, reporting a gestational age of median 6.5 weeks, compared with median 10 weeks gestation for the group who received regular care (table 2). The group receiving the midwife-led model of care had median nine antenatal visits, and only two women reported less than four visits, while the group receiving regular care had median six antenatal visits and 28 women reported having less than four visits at the governmental clinic. While $42 \%$ in the midwife-led group, received antenatal care exclusively from the governmental clinic, only $8 \%$ in the regular care group reported the same. Subsequently, women who had regular care received more additional care from private doctors and $33 \%$ gave birth at a private hospital, compared with only $11 \%$ of women who received the midwife-led care. There were no missing data except two women in the group receiving midwife-led care, who gave birth under transportation and therefore did not report satisfaction with intrapartum care. Only women who had received the midwife-led continuity model of care received home visit after birth.

\section{Satisfaction with care}

The groups' mean sum-scores, including crude and adjusted mean differences in satisfaction with care, are given in table 3 . For the primary outcome, a statistically significant higher satisfaction with care was observed in favour of the group receiving the midwife-led care, through the continuum of pregnancy, intrapartum and postnatal period, with a crude mean sum-score of 5.2 (SD 0.86 ) versus 4.8 (SD 0.96) in the group receiving regular care. The adjusted mean difference between the groups was $0.6(95 \%$ CI 0.35 to 0.83$), \mathrm{p}<0.0001$. The statistically significant difference in favour of the midwife-led model persisted during the various periods of care. The adjusted mean difference in satisfaction with care during pregnancy was 0.4 ( 0.06 to 0.65$), \mathrm{p}=0.021$ and with care during labour and birth 0.5 ( 0.14 to 0.87 ), $\mathrm{p}=0.008$. The highest difference in satisfaction was with postpartum care, an adjusted mean difference of 0.8 (0.53 to 1.16), $\mathrm{p}<0.0001$. Adjusting for the number of women who had given birth in private hospitals, influenced, but did not significantly change the primary outcome. Neither did it change satisfaction with care during pregnancy or postnatal period. However, a significant higher proportion of women who received regular care gave birth in private hospitals and adjusting for this factor significantly changed the difference in satisfaction with intrapartum care in governmental hospitals, in favour of the midwife-led model. We did not adjust for age, parity, employment, time since birth or if the parents lived in the same village, as we found no significant influence from these covariates in univariate analyses. The satisfaction with care during home visits was generally high. However, it only applied to the group receiving the midwife-led continuity model of care. The detailed results in the full scales are presented in online supplementary file 2 and shows which aspects of care that influenced the difference between the groups. This 
Table 3 Satisfaction with antenatal, intrapartum and postpartum care

\begin{tabular}{|c|c|c|c|c|c|}
\hline & \multicolumn{2}{|c|}{ Mean sum-scores* } & \multirow{2}{*}{$\begin{array}{l}\text { Crude difference } \\
\text { Mean }(95 \% \mathrm{Cl})\end{array}$} & \multicolumn{2}{|c|}{ Adjusted difference } \\
\hline & $\begin{array}{l}\text { Midwife- } \\
\text { led care‡ }\end{array}$ & $\begin{array}{l}\text { Regular } \\
\text { care‡ }\end{array}$ & & $\begin{array}{l}\text { Adjusted mean } \\
(95 \% \mathrm{Cl})\end{array}$ & $\begin{array}{l}\text { Adjusted } \\
P \text { value }\end{array}$ \\
\hline $\begin{array}{l}\text { Satisfaction with all care through the whole continuum } \\
\text { (53)§ }\end{array}$ & $5.2(0.86)$ & $4.8(0.96)$ & $0.5(0.25$ to 0.73$)$ & 0.6 (0.37 to 0.81$)$ & $<0.0001$ \\
\hline \multicolumn{6}{|l|}{ Descriptive outcomes } \\
\hline Satisfaction with pregnancy care from doctors (5)§ & $5.4(1.50)$ & $5.2(1.47)$ & $0.2(-0.18$ to 0.66$)$ & $\begin{array}{l}0.2(-0.23 \text { to } \\
0.55)\end{array}$ & 0.351 \\
\hline Satisfaction with all care during pregnancy $(15) \S$ & $5.7(0.99)$ & $5.3(1.19)$ & $0.4(0.08$ to 0.68$)$ & 0.4 (0.06 to 0.64$)$ & 0.021 \\
\hline $\begin{array}{l}\text { Satisfaction with midwives' care during labour and birth } \\
\text { (5)§ }\end{array}$ & $5.5(1.75)$ & $5.1(1.79)$ & $0.5(-0.04$ to 0.93$)$ & $0.7(0.21$ to 1.13$)$ & 0.008 \\
\hline Satisfaction with all care during labour and birth (17)§ & $5.1(1.29)$ & $4.7(1.34)$ & $0.3(-0.04$ to 0.68$)$ & 0.5 (0.18 to 0.83$)$ & 0.006 \\
\hline $\begin{array}{l}\text { Satisfaction with care and advice related to baby after } \\
\text { birth (5)§ }\end{array}$ & $4.8(1.23)$ & $4.1(1.44)$ & 0.7 (0.41 to 1.01$)$ & 0.8 (0.44 to 1.21$)$ & $<0.0001$ \\
\hline Satisfaction with care related to yourself after birth (9)§ & $5.0(1.07)$ & $4.3(1.1)$ & $0.8(0.37$ to 1.11$)$ & $0.8(0.44$ to 1.08$)$ & $<0.0001$ \\
\hline Satisfaction with all care after birth $(21) \S$ & $5.0(1.04)$ & $4.2(1.14)$ & $0.8(0.46$ to 1.08$)$ & $0.8(0.50$ to 1.19$)$ & $<0.0001$ \\
\hline
\end{tabular}

*Mean (SD) sum-score is calculated from the 1-7 likert scale where 1 means very low satisfaction and 7 means very high.

†Bias-correctedand accelerated estimates with $95 \%$ Cls, analysed by bootstrapping linear regression, adjusted for place of birth (private or governmental hospital).

$\ddagger 100$ women in each group, no missing except two women who gave birth under transportation in the group receiving midwife led care did not report satisfaction with care during labour and birth.

$\S$, Numbers in bracets reflects the numbers of questions included in teh sum score.

scale also reveal that both groups scored equally high in wishing that someone from their family could accompany them during birth.

\section{Breastfeeding}

As the interview was done at an approximately equal time point of median 16 weeks after birth in both groups we compared the proportion of women who were still breastfeeding. Most women were still breastfeeding at this time point, respectively $96 \%$ receiving midwife-led care and $88 \%$ receiving regular care (table 4 ). Of these a statistically significant higher rate of women receiving midwife-led care were still exclusively breastfeeding, $67 \%$ versus $46 \%$. After adjusting for age, parity and number of weeks since birth the difference was still statistically significant with an adjusted OR of 2.56 (95\% CI 1.35 to $4.89), p=0.004$. Only three women in the control group had never breastfed, and none in the midwife-led group.

\section{Continuity measures}

Women who received regular care reported they often met the same provider during antenatal care, none in the control group reported they met the healthcare provider again during hospital or postnatal care. While investigating the midwife-led model's actual continuity with care from the same midwife through the continuum (table 5), we found that $23 \%$ of the women received care from

Table 4 Breastfeeding practice

\begin{tabular}{|c|c|c|c|c|c|}
\hline & \multirow[b]{2}{*}{$\begin{array}{l}\text { Midwife-led } \\
\text { care* }^{\star}\end{array}$} & \multirow[b]{2}{*}{$\begin{array}{l}\text { Regular } \\
\text { care* }^{*}\end{array}$} & \multicolumn{3}{|c|}{ Difference between groups $†$} \\
\hline & & & OR (95\% Cl) & $\begin{array}{l}\text { Adjusted OR } \\
(95 \% \mathrm{Cl})\end{array}$ & $\begin{array}{l}\text { Adjusted } \\
\text { P value }\end{array}$ \\
\hline Still breastfeeding (exclusively and partly) & $96 \%$ & $88 \%$ & 3.27 (1.02 to 10.52$)$ & 2.76 (0.84 to 9.09$)$ & 0.096 \\
\hline Never breastfed & 0 & $3 \%$ & & & 0.246 \\
\hline
\end{tabular}

*100 women answered, no missing.

†OR with $95 \% \mathrm{Cls}$ from binary logistic regression analysis, adjusted for age, parity and time point of interview/weeks since birth, regular care was set as reference. 
Table 5 Continuity measures $(n=100)$

$\%$

Number who met their ANC midwife during labour 23

Number who met their ANC midwife at hospital's 34 postnatal ward

Number who met their ANC midwife at home visit 69

Number who met their ANC midwife through the 17 whole continuum

\begin{tabular}{ll} 
Number who only met their midwife in ANC & 8 \\
Numbers of meetings with the same provider & $8(7-9)^{*}$ \\
\hline
\end{tabular}

$\mathrm{n}=$ number of women, only from the group receiving midwife-led care

${ }^{*}$ median (IQR).

ANC, antenatal care.

their antenatal-midwife during labour, and $34 \%$ received care from her at the hospital's postnatal ward. Of the 100 women, $69 \%$ received home visit from their antenatalmidwife, while $7 \%$ received home visits from the nurse who they also knew from the clinic. As many as $17 \%$ met their antenatal midwife through the whole continuum of antenatal, intrapartum and postnatal period, while $8 \%$ did not receive care from their antenatal midwife elsewhere.

\section{Women's recommendations}

Free text recommendations to improve governmental services were recorded from 101 women, 76 from the group receiving regular care and 24 from the group receiving midwife-led care. The recommendations were organised in 13 themes and coded in an Excel sheet where their frequencies were calculated. The most prominent recommendation, expressed from 38 women were to allow bringing a companion to join them during labour and birth, 35 women recommended more human, respectful and sensitive care during labour and birth, while 24 women recommended to implement an appointment system for the antenatal visits.

\section{DISCUSSION}

Compared with regular care, the midwife-led model was associated with a higher sum-score of satisfaction with care through the continuum of antenatal, intrapartum and postpartum period. The highest satisfaction reported in both groups, were with care during pregnancy, where the mean sum-score differed least. The difference between groups during pregnancy was most prominent related to satisfaction with being involved and the emotional support from the midwives. The general high satisfaction with pregnancy care could be explained by that this period is less demanding and stressful for most women and recall bias might have influenced. Care during labour and birth was presented with the lowest satisfaction scores in both groups. This is not surprising considering the overcrowded and understaffed environment in the government hospitals labour wards, as previously described by other studies from Palestine. ${ }^{15}{ }^{16}$ Another important explanation could be the statement from a clear majority of women in both groups: 'I wish someone from my family could accompany me during labour and birth'. The request of having a companion during labour was confirmed by the women's main recommendation. The value of a companion is important to improve birth outcomes and improve women's birth experiences. ${ }^{22}$ WHO recommends that health facilities gives every woman the option to experience labour with a companion of her choice. ${ }^{23}$ Nevertheless, knowing a midwife at the labour ward seemed to influence the difference between the two groups' satisfaction with care during labour and birth, a difference that increased after adjusting for the subgroup of women who gave birth in private hospitals. Interestingly, the difference in satisfaction with care from doctors also increased to a significant level after this adjustment. This suggests that the enhanced relation between the woman and her midwife also seemed to reduce the alienation to doctors. An important contextual question revealed that women receiving the midwife-led model were less afraid of being stopped at Israeli military checkpoints on their way from the village to hospital. This reduced anxiety could be related to that women's relation with their midwife made them feel safer, also knowing they could call their midwife in an emergency. The increased satisfaction with care during the intrapartum period among women receiving midwife-led care, could reasonably be explained by that nearly a quarter was cared for during labour by the midwife they knew. The relational continuity seemed to enhance women's perception of receiving respectful care during labour and birth. The most prominent difference between the two groups' satisfaction was with care during postpartum period, despite the exclusion of the high score of satisfaction with care related to home visits. The highest difference between the groups was seen in satisfaction with care at the postnatal ward and could be explained by the high number who met their midwife from pregnancy there. The difference between the group's satisfaction with care in this study seems to be less prominent compared with studies of satisfaction with continuity models of care in high-income countries. ${ }^{20}$ Nevertheless, this study confirms the general findings of improved satisfaction with midwife-led continuity models of care. ${ }^{82024-26}$

The results from this study also demonstrate an association between receiving the midwife-led model of care and increased duration of exclusive breastfeeding. The midwife-led model provided continuity with breastfeeding information and support during pregnancy and after birth in hospital and home visits. McFadden et al concluded in a systematic review that predictable, standard breastfeeding support during antenatal and/ or postnatal care, tailored to women's needs and given face-to-face, seem to increase duration of exclusive breastfeeding. ${ }^{27}$ Continuous postnatal breastfeeding support is also recommended. ${ }^{28}$ Exclusive breastfeeding up to 
6 months in life is considered an important protection against infections, malocclusions and breastfeeding have in general several long-term health benefits both for women and their children. ${ }^{29}$ Although midwives were prevented from being on call, a high number of women receiving the midwife-led model were cared for during labour and at the postnatal ward by the midwife they knew. The high rate of continuity was possible because all midwives worked full-time at the hospital beside their outreaching programme once a week.

This study implies that midwife-led continuity contributes to sustainable improvements within a system with limited resources, enabling midwives to improve quality of care to vulnerable women in their own population. The experience and findings from this implementation are an important contribution to reach the United Nations Sustainable Development Goal number 3 towards 2030, promising good health and well-being for all. ${ }^{30}$

\section{Limitations and strengths}

The main limitation of this study is the observational, retrospective design comparing groups with potential unmeasured confounders. Because the model had already been implemented randomisation was not possible. It would have been an advantage to know village of origin and in which governmental hospital the women gave birth, as it could represent potential bias. However, the women in both groups represented a quite similar rural population from villages in different regions in the West Bank.

Investigating such complex and sensitive outcomes of an implementation in a low-middle income setting is the main strength of this study. The pragmatic and novel approach, adapting the model to the Palestinian context and implementing it within the public health system provided a unique experience of how midwife-led continuity of care can work in a low-middle income setting. Engagement from local midwives, nurses and doctors who have been deeply involved in developing and adapting the model to the context, facilitated anchoring the model in the Palestinian public health system. The model was implemented with Norwegian funding in six governmental hospitals and 37 villages in the West Bank, but since February 2017 it has been administrated and sustained by the Palestinian Ministry of Health. ${ }^{31}$ A strength of the study is the focus on satisfaction with care provided to the poorer part of the population, who are in most need of quality improvements. Another strength is the comprehensive questionnaire with a Likert scale used in previous studies that measured satisfaction with midwife-led continuity models, using the recommended focus on women's satisfaction with process of care and interpersonal behaviour throughout the continuum. ${ }^{51320} 24$

\section{CONCLUSION}

This study has investigated a midwife-led continuity model of care that has been adapted to a low-middle income setting under long-term military occupation.
The findings indicate that midwife-led continuity of care is associated with improved satisfaction with care also in such settings. There are increased user expectations for qualitative and safe care in low- and middle-income countries, including respectful and sensitive care. ${ }^{9} 32$ Further qualitative research could investigate how and why women find this model useful. There is a high potential to improve quality of maternal care in Palestine, by increasing number of midwives, by introducing more privacy in the labour ward to facilitate that women can experience labour with a companion of their choice and by introducing midwife-led continuity of care to more women.

\section{Author affiliations}

${ }^{1}$ Oslo University Hospital The Intervention Centre, Oslo, Norway

${ }^{2}$ Faculty of Medicine, University of Oslo, Oslo, Norway

${ }^{3}$ Oslo Centre for Biostatistics and Epidemiology, University of Oslo, Oslo, Norway

${ }^{4}$ Faculty of Health Sciences, Oslo Metropolitan University, Oslo, Norway

${ }^{5}$ Faculty of Health and Social Sciences, University of Southeast Norway, Oslo, Norway, Oslo, Norway

${ }^{6}$ Department of Obstetrics, Oslo University Hospital, Ullevål, Oslo, Norway

${ }^{7}$ Faculty of Health Professions, Al Quds University, Jerusalem, Palestine

${ }^{8}$ Faculty of Nursing and Health Sciences, Bethlehem University, Bethlehem,

Palestine

Acknowledgements First and foremost, we want to thank all the women who participated in this study and gave us valuable insight in their perception of the care they received. We thank Arsan Aghazarian for translating the questionnaire, and the midwives who gave contextual advice in the translation. We finally want to thank the Palestinian Ministry of Health for implementing the model and facilitating the study, the clinic's nurses and doctors for their collaboration and especially the courageous midwives who reach out to provide care to women and babies in occupied Palestine.

Contributors BM was involved with the Implementation, study design, preparation of data collection, data analysis, data interpretation and writing. LMD was involved with study design, data analysis and writing. MiL was involved with study design, data interpretation and writing. MaL was involved with study design, data interpretation and writing. ID and DE were involved with the data collection and data interpretation. EF was involved in study design, data collection, data analysis, data interpretation and writing. BM drafted the article and tables. All authors have reviewed and approved the final manuscript. The corresponding author had full access to all the data in the study and had final responsibility for the decision to submit for publication.

Funding This work was partly supported by the Research Council of Norway through the Global Health and Vaccination Program (GLOBVAC), project number 243706. The implementation of the midwife-led continuity model of care received public funding through the humanitarian, non-profit organization Norwegian Aid Committee (NORWAC).

Competing interests EF is director of NORWAC. BM was partly employed by NORWAC until February 2017 as project manager for implementing the model.

Patient consent for publication Not required.

Ethics approval The study was approved by the Norwegian Regional Committee for Medical Health research Ethics South East (REK); ID number: 2015/1235. It was also approved by the Palestinian Ministry of Health.

Provenance and peer review Not commissioned; externally peer reviewed.

Data availability statement Data are available upon reasonable request. All data relevant to the study are included in the article or uploaded as supplementary information.

Open access This is an open access article distributed in accordance with the Creative Commons Attribution Non Commercial (CC BY-NC 4.0) license, which permits others to distribute, remix, adapt, build upon this work noncommercially, and license their derivative works on different terms, provided the original work is properly cited, appropriate credit is given, any changes made 
indicated, and the use is non-commercial. See: http://creativecommons.org/ licenses/by-nc/4.0/.

\section{ORCID iD}

Berit Mortensen http://orcid.org/0000-0002-1036-7338

\section{REFERENCES}

1 Miller S, Abalos E, Chamillard M, et al. Beyond too little, too late and too much, too soon: a pathway towards evidence-based, respectful maternity care worldwide. Lancet 2016;388:2176-92.

2 Geller SE, Koch AR, Garland CE, et al. A global view of severe maternal morbidity: moving beyond maternal mortality. Reprod Health 2018;15:98.

3 Bohren MA, Vogel JP, Hunter EC, et al. The mistreatment of women during childbirth in health facilities globally: a mixed-methods systematic review. PLoS Med 2015;12:e1001847.

4 Lukasse M, Schroll A-M, Karro H, et al. Prevalence of experienced abuse in healthcare and associated obstetric characteristics in six European countries. Acta Obstet Gynecol Scand 2015;94:508-17.

5 Srivastava A, Avan BI, Rajbangshi P, et al. Determinants of women's satisfaction with maternal health care: a review of literature from developing countries. BMC Pregnancy Childbirth 2015;15:97.

6 Sando D, Abuya T, Asefa A, et al. Methods used in prevalence studies of disrespect and abuse during facility based childbirth: lessons learned. Reprod Health 2017;14:127.

7 World Health Organisation. Who recommendations on antenatal care for a positive pregnancy experience. World Health Organization, 2016: 152. http://apps.who.int/iris/bitstream/10665/250796/1/ 9789241549912-eng.pdf?ua=1

8 Sandall J, Soltani H, Gates S, et al. Midwife-led continuity models versus other models of care for childbearing women. Cochrane Database Syst Rev 2016;4:CD004667.

9 Van Lerberghe W, Matthews Z, Achadi E, et al. Country experience with strengthening of health systems and deployment of midwives in countries with high maternal mortality. Lancet 2014;384:1215-25.

10 Nair M, Yoshida S, Lambrechts T, et al. Facilitators and barriers to quality of care in maternal, newborn and child health: a global situational analysis through metareview. BMJ Open 2014;4:e004749.

11 Homer CSE, Friberg IK, Dias MAB, et al. The projected effect of scaling up midwifery. Lancet 2014;384:1146-57.

12 Homer C, Brodie P, Leap N. Midwifery continuity of care : a practical guide. Sydney ; New York: Churchill Livingstone/Elsevier, 2008.

13 Perriman N, Davis D. Measuring maternal satisfaction with maternity care: a systematic integrative review: what is the most appropriate, reliable and valid tool that can be used to measure maternal satisfaction with continuity of maternity care? Women Birth 2016;29:293-9.

14 Wick L, Mikki N, Giacaman R, et al. Childbirth in Palestine. Int J Gynaecol Obstet 2005;89:174-8.

15 Rahim HFA, Wick L, Halileh S, et al. Maternal and child health in the occupied Palestinian Territory. Lancet 2009;373:967-77.
16 Giacaman R, Abu-Rmeileh NME, Wick L. The limitations on choice: Palestinian women's childbirth location, dissatisfaction with the place of birth and determinants. Eur J Public Health 2007;17:86-91.

17 Mortensen B, Lukasse M, Diep LM, et al. Can a midwife-led continuity model improve maternal services in a low-resource setting? A non-randomised cluster intervention study in Palestine. BMJ Open 2018;8:e019568.

18 Mortensen B, Lieng M, Diep LM, et al. Improving maternal and neonatal health by a midwife-led continuity model of care - an observational study in one governmental hospital in Palestine. EClinicalMedicine 2019;10:84-91.

19 Mortensen $\mathrm{B}$. To be veiled or not to be - what unites is the question, Experiences from a continuity of Midwifery Care Model in Palestine and Norway. Master's thesis. Bodø, Norway: University of Nordland, 2011: 121.

20 Forster DA, McLachlan HL, Davey M-A, et al. Continuity of care by a primary midwife (caseload midwifery) increases women's satisfaction with antenatal, intrapartum and postpartum care: results from the COSMOS randomised controlled trial. BMC Pregnancy Childbirth 2016;16:28.

21 Waldenstrom U, Rudman A. Satisfaction with maternity care: how to measure and what to do. Women's Health 2008;4:211-4.

22 Bohren MA, Hofmeyr GJ, Sakala C, et al. Continuous support for women during childbirth. Cochrane Database Syst Rev 2017;7:CD003766.

23 World Health Organisation. Standards for improving quality of maternal and newborn care in health facilities. WHO, 2016. http:// apps.who.int/iris/bitstream/10665/249155/1/9789241511216-eng. pdf?ua $=1$

24 Waldenstrom U, Brown S, McLachlan H, et al. Does team midwife care increase satisfaction with antenatal, intrapartum, and postpartum care? A randomized controlled trial. Birth 2000;27:156-67.

25 Fereday J, Collins C, Turnbull D, et al. An evaluation of midwifery group practice. Part II: women's satisfaction. Women Birth 2009;22:11-16.

26 Harvey S, Rach D, Stainton MC, et al. Evaluation of satisfaction with midwifery care. Midwifery 2002;18:260-7.

27 McFadden A, Gavine A, Renfrew MJ, et al. Support for healthy breastfeeding mothers with healthy term babies. Cochrane Database Syst Rev 2017;2:CD001141.

28 Zhang Z, Zhu Y, Zhang L, et al. What factors influence exclusive breastfeeding based on the theory of planned behaviour. Midwifery 2018;62:177-82.

29 Victora CG, Bahl R, Barros AJD, et al. Breastfeeding in the 21st century: epidemiology, mechanisms, and lifelong effect. Lancet 2016;387:475-90.

30 ten Hoope-Bender P, Lopes STC, Nove A, et al. Midwifery 2030: a woman's pathway to health. What does this mean? Midwifery 2016;32:1-6.

31 Mortensen B. Palestinian midwives on the front line. Journal of Middle East Women's Studies 2018;14:379-83.

32 ten Hoope-Bender P, de Bernis L, Campbell J, et al. Improvement of maternal and newborn health through midwifery. Lancet 2014;384:1226-35. 